\title{
Carbon monoxide gas sensing properties of Ga-doped ZnO film grown by ion plating with DC arc discharge
}

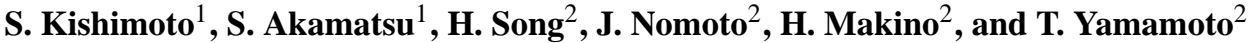 \\ ${ }^{1}$ National Institute of Technology, Kochi College, Nankoku-shi, Japan \\ ${ }^{2}$ Kochi University of Technology, Kami-shi, Japan \\ Correspondence to: S. Kishimoto (kishi@me.kochi-ct.ac.jp)
}

Received: 28 July 2014 - Revised: 9 November 2014 - Accepted: 11 November 2014 - Published: 10 December 2014

\begin{abstract}
The carbon monoxide (CO) gas sensing properties of low-resistance heavily Ga-doped $\mathrm{ZnO}$ thin films were evaluated. The $\mathrm{ZnO}$ films with a thickness of $50 \mathrm{~nm}$ were deposited at $200^{\circ} \mathrm{C}$ by ion plating. The electrical properties of the $\mathrm{ZnO}$ films were controlled by varying the oxygen assist gas flow rate during deposition. The $\mathrm{CO}$ gas sensitivity of $\mathrm{ZnO}$ films with Au electrodes was investigated in nitrogen gas at a temperature of 230 to $330^{\circ} \mathrm{C}$. $\mathrm{CO}$ gas concentration was varied in the range of $0.6-2.4 \%$ in nitrogen gas. Upon exposure to $\mathrm{CO}$ gas, the current flowing through the film was found to decrease. This response occurred even at the lowest temperature of $230^{\circ} \mathrm{C}$, and is thought to be the result of a mechanism different than the previously reported chemical reaction.
\end{abstract}

\section{Introduction}

$\mathrm{ZnO}$ is a substance for which various applications such as gas sensors and ultraviolet light sensors are anticipated. In recent years, the properties and applications of $\mathrm{ZnO}$ nanostructured films have been also studied (Zhao et al., 2010; Lao et al., 2003).

Carbon monoxide (CO) gas, being both colorless and odorless, is a dangerous gas for which it is hoped that highsensitivity sensors may be developed. The lethal concentration by $\mathrm{CO}$ gas is $1500 \mathrm{ppm}$. There have been a number of attempts to evaluate the sensitivity of $\mathrm{ZnO}$ to $\mathrm{CO}$ gas. There have also been reports of carbon nanorods and nanowires reacting with high sensitivity to $\mathrm{CO}$ gas (Hassan et al., 2013; Kim et al., 2009). Experiments using catalysts such as Pd have also been reported (Trung et al., 2014). In these cases, the response mechanism is understood to have involved chemical reactions between gas molecules and the $\mathrm{ZnO}$ surface. All of these films had a high electrical resistance, and the presence of the gas was indicated by a change in resistance. Several investigations have been conducted on $\mathrm{CO}$ gas sensing properties of Ga-doped $\mathrm{ZnO}$ nanostructured films (Han et al., 2011; Pearce et al., 2009; Phan and Chung, 2013). Phan and Chung (2013) have reported the effects of $\mathrm{Ga}$-doping on $\mathrm{CO}$ sensing properties of $\mathrm{Ga}$-doped $\mathrm{ZnO}$ nanorods. Their $\mathrm{p}-\mathrm{n}$ junctions-based nanorods sensors have a fast response.

We have previously reported transparent low-resistance Ga-doped $\mathrm{ZnO}$ (GZO) films produced using ion plating (Shirakata et al., 2003; Yamada et al., 2007a, b, 2010). In the present study, we carried out an evaluation of the sensitivity of these polycrystalline $\mathrm{ZnO}$ thin films to $\mathrm{CO}$ gas.

\section{Experimental}

The polycrystalline $\mathrm{ZnO}$ films were grown using DC arc discharge ion plating (Yamamoto et al., 2012). The growth temperature was $200^{\circ} \mathrm{C}$ and a $\mathrm{ZnO}$ tablet incorporating $3 \mathrm{wt} \%$ $\mathrm{Ga}$ was used as the source material. During growth, flowing oxygen was used as an assist gas, with the flow rate being varied between $5-25 \mathrm{~cm}^{3}$ in order to control the structure and properties of the films. The film thickness, controlled by means of the growth time, was $50 \mathrm{~nm}$. In the previous report, Ga 3 wt \%-doped $\mathrm{ZnO}$ film was good polycrystalline with a hexagonal structure (Yamada et al., 2006).

The crystallinity of the films was characterized by highresolution X-ray diffraction (XRD; ATX-G, RIGAKU). Their electrical properties were evaluated by Hall-effect measurements (HL5500PC, Nonometrics) in the van der Pauw configuration at room temperature. 


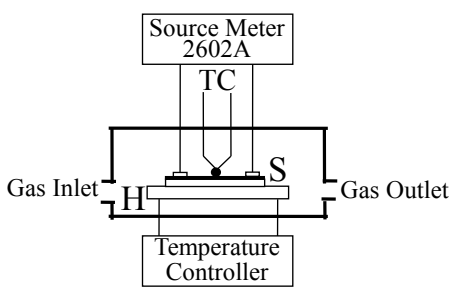

(a)

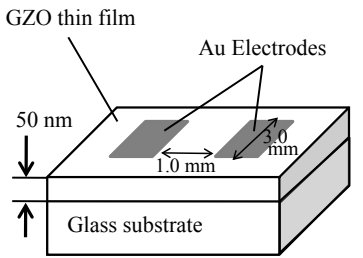

(b)
Figure 1. Schematic diagrams of (a) measurement setup and (b) sample dimension. TC: thermocouple; H: heater; S: Ga-doped $\mathrm{ZnO}$ film on glass substrate.

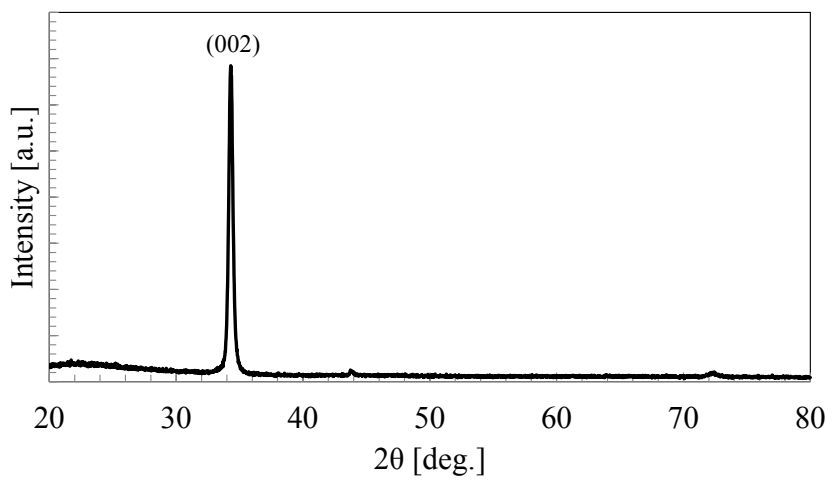

Figure 2. High-resolution XRD pattern result of the $\mathrm{ZnO}$ film with $50 \mathrm{~nm}$ thickness.

Evaluation of the gas sensitivity was performed using the following method. Figure 1 shows the layout of the sample and electrodes along with the sample chamber. First, Au electrodes (separated by $1 \mathrm{~mm}$ ) were formed with a thickness of at least $150 \mathrm{~nm}$, and the sample was cut into $5 \mathrm{~mm} \times 5 \mathrm{~mm}$ chips, which were placed in a compact chamber for evaluation. The electrodes of the $\mathrm{ZnO}$ film were connected to a DC power supply (System SourceMeter 2602A, Keithley), which applied $5 \mathrm{~V}$, and this current was measured for the films. The temperature of the sample films was controlled at between 230 and $330^{\circ} \mathrm{C}$ using a ceramic heater set beneath the sample. These temperatures are slightly higher than the desorption temperatures of oxygen from metal oxide (Iwamoto et al., 1978). The sample chamber was flowed continuously with nitrogen gas at a flow rate of $400 \mathrm{sccm}$. In order to evaluate the intrinsic reaction to $\mathrm{CO}$ gas, $\mathrm{CO}$ gas sensing properties were investigated in nitrogen gas. Under these conditions, the amount of $\mathrm{CO}$ gas necessary to produce the specified concentration was mixed with the nitrogen gas and allowed to flow for $10 \mathrm{~s}$, and the change in the sample current was measured. In order to maintain the reaction satisfactorily, the evaluation was conducted at an extremely high $\mathrm{CO}$ gas concentration of $2.5(0.6 \%)$ to $10(2.4 \%) \mathrm{sccm}$. The gas was evacuated and released at atmospheric pressure. The gas inlet was placed in such a way that the gas entering the sample
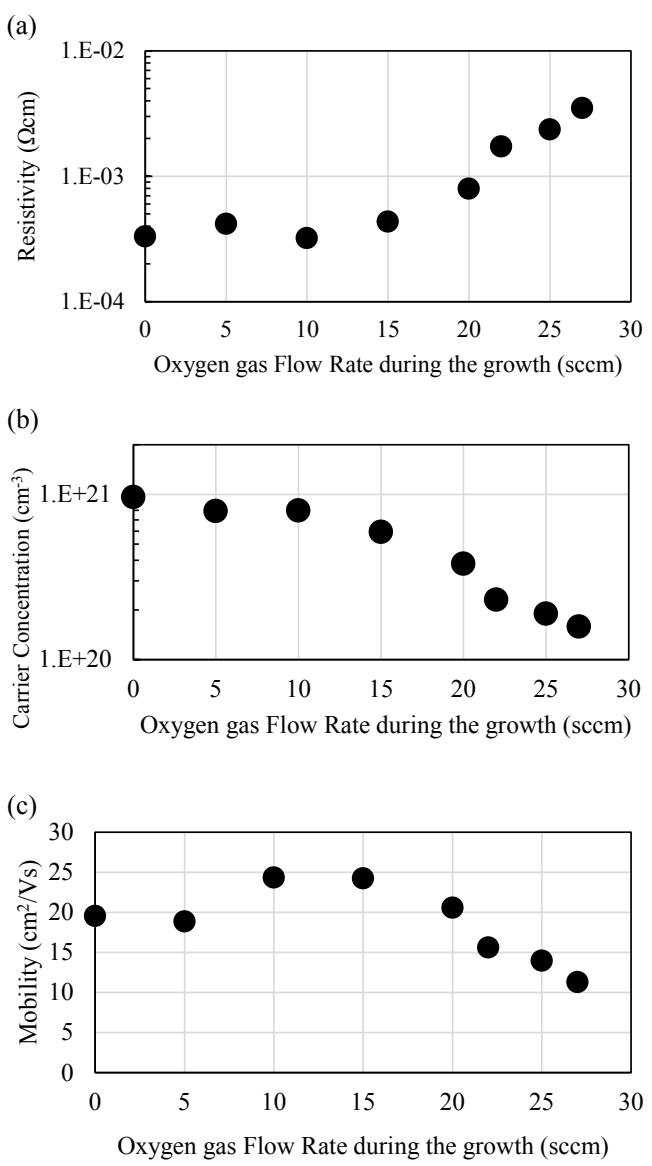

Figure 3. Resistivity as a function of oxygen gas flow rate for GZO films (a). Carrier concentration as a function of oxygen flow rate for GZO films (b). Hall mobility as a function of oxygen flow rate for GZO films (c).

chamber did not directly impinge on the sample. The volume of the cylindrical sample chamber was approximately $200 \mathrm{~cm}^{3}$.

\section{Results and discussions}

Figure 2 shows the XRD results for the deposited $\mathrm{ZnO}$ films. It can be seen that the main diffraction peak is associated with (002) planes, so that the film is $c$ axis oriented. Under the same growth condition, these Ga-doped $\mathrm{ZnO}$ films were polycrystalline with a wurtzite-type hexagonal structure from a cross-section transmission electron microscopy (TEM) and in-plane XRD measurements (Yamada et al., 2007b).

Figure 3 shows the results of Hall-effect measurements for the samples. Due to the Ga doping, the resistivity was extremely low. The carrier concentration was found to decrease with increasing oxygen flow rate during growth. In all cases, the carrier concentration was $\geq 1.0 \times 10^{20} \mathrm{~cm}^{-3}$ and, from the temperature dependence of the Hall-effect measurement for samples deposited under same conditions, it was found 


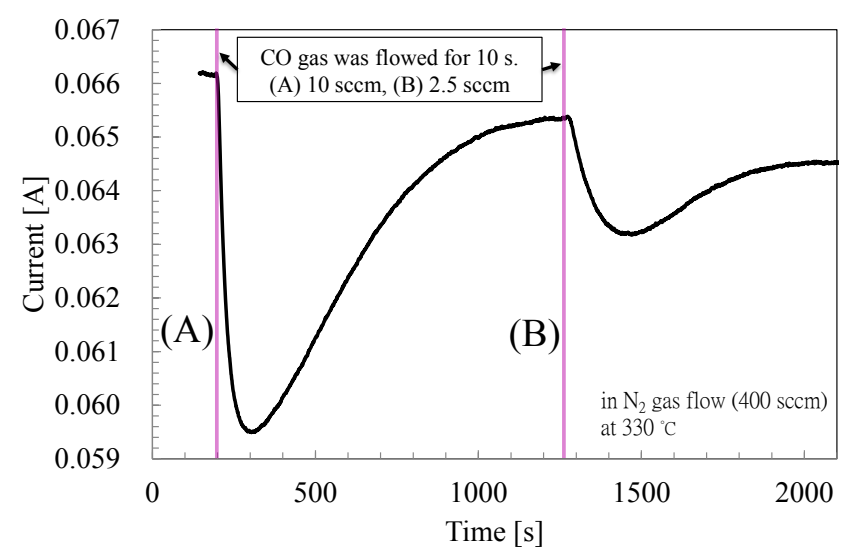

Figure 4. Changes in current in $\mathrm{ZnO}$ films at $330^{\circ} \mathrm{C}$ due to $\mathrm{CO}$ gas. A constant nitrogen gas flow of $400 \mathrm{sccm}$ was used and $\mathrm{CO}$ gas was allowed to flow for $10 \mathrm{~s}$.

that the samples were degenerated. From studies of samples deposited under the same conditions (Yamamoto et al., 2012), both intra-grain scattering and grain boundary scattering are the mechanisms limiting carrier transport.

Figure 4 shows the change in the film current when a sample (oxygen gas flow rate during the growth was $25 \mathrm{sccm}$ ) was exposed to a flow of $\mathrm{CO}$ gas. In addition to the $400 \mathrm{sccm}$ flow of nitrogen gas, 10 and then $2.5 \mathrm{sccm}$ of $\mathrm{CO}$ were sequentially flowed for $10 \mathrm{~s}$, and the change in sample current was measured. The current prior to exposure is determined by the original film resistance. The current shows a decrease upon exposure to the gas, with a minimum occurring at around $100 \mathrm{~s}$ following exposure, before showing a tendency to return to its original value. Previously, it was reported that exposure to $\mathrm{CO}$ caused a decrease in the resistance of $\mathrm{ZnO}$ film due to the chemical reaction (Tanaka et al., 1976) occurring on the surface given in

$\mathrm{CO}_{(\mathrm{g})}+\mathrm{O}_{(\mathrm{ads})}^{-} \rightarrow \mathrm{CO}_{2(\mathrm{~g})}+e^{-}$.

Since the results shown in Fig. 3 indicate the opposite behavior, the mechanism must be different than that previously reported. In other words, it does not involve a chemical reaction with $\mathrm{CO}$ molecules on the film surface. It may be that the absorption to the grain boundary of oxygen gas molecules plays the role of a physical barrier for carriers.

In fact, since even at $330{ }^{\circ} \mathrm{C}$ there is a large response of several milliamps, it is thought that the reaction involves the entire film rather than just the surface. Since it is difficult to imagine the reaction occurring within the grains in the polycrystalline film, it is possible that it is actually taking place at the grain boundaries. For samples with a relatively low carrier concentration and Hall mobility, the current showed a large decrease of about $5.0 \mathrm{~mA}$ at a temperature of $330^{\circ} \mathrm{C}$ in response to $\mathrm{CO}$ gas. The large current response observed in the present study clearly indicates the practical potential of a ZnO-based $\mathrm{CO}$ detector.

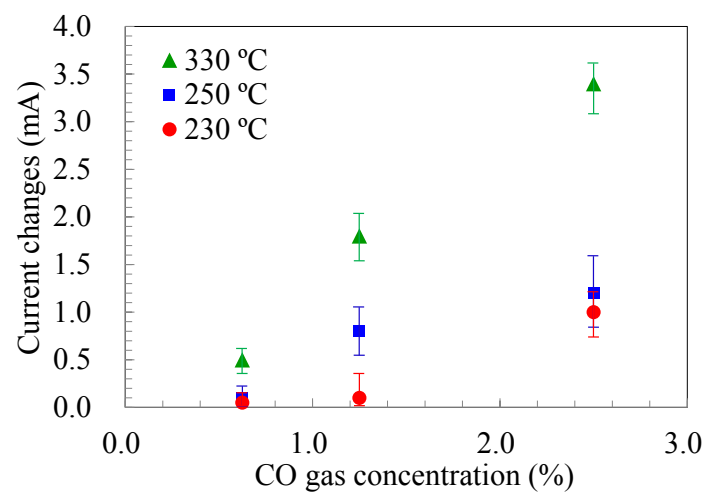

Figure 5. Dependence of current change in $\mathrm{ZnO}$ films on $\mathrm{CO}$ gas concentration. The carrier concentration was $1.8 \times 10^{20} \mathrm{~cm}^{-3}$. The sample temperatures were 230,250 and $330^{\circ} \mathrm{C}$.

Figure 5 shows the change in the current response as a function of $\mathrm{CO}$ gas concentration. The current change increased with increasing the $\mathrm{CO}$ gas concentration. Furthermore, even at a low temperature of $230^{\circ} \mathrm{C}$, a large decrease in current was found in response to $\mathrm{CO}$ gas. For the elucidation of the reaction mechanism, it requires further experiments.

\section{Conclusions}

The reaction characteristics of heavily Ga-doped lowresistance $\mathrm{ZnO}$ films in response to $\mathrm{CO}$ gas were investigated. The $\mathrm{ZnO}$ thin films were polycrystalline with a columnar structure and were highly oriented along the $c$ axis. In response to an inflow of $\mathrm{CO}$ gas, the current flowing through the film was found to decrease, which is the opposite to the previously reported effect associated with a chemical reaction on the film surface.

In the present study, a $\mathrm{CO}$ gas concentration of $6.21 \%$ was chosen in order to observe the reaction clearly, and a large reaction current of $2 \mathrm{~mA}$ was obtained. This may have been the result of the heavy Ga doping level.

Acknowledgements. This work has been supported by JSPS KAKENHI grant no. 30320120. 2012-2014.

Edited by: M. Meyyappan

Reviewed by: two anonymous referees

\section{References}

Han, N., Liu, H., Wu, X., Li, D., Chai, L., and Chen, Y.: Pure and Sn-, Ga- and Mn-doped $\mathrm{ZnO}$ gas sensors working at defferent temperature for formaldehyde, humidity, $\mathrm{NH}_{3}$, toluene and $\mathrm{CO}$, Appl. Phys. A-Mater., 104, 627-633, 2011.

Hassan, J. J., Mahdi, M. A., Chin, C. W., Abu-Hassan, and Hassan, H. Z.: A high-sensitivity room-temperature hydrogen gas sensor 
based on oblique and vertical ZoN nanorod arrays, Sensors Actuat. B-Chem., 176, 360-367, 2013.

Iwamoto, M., Yoda Y., Yamazoe, N., and Seiyama, T.: Study of Metal Oxide Catalysts by Temprerature Programmed Desorption, J. Phys. Chem., 82, 2564-2570, 1978.

Kim, K., Song, Y., Chang, S., Kim, I., Kim, S., and Lee, S. Y.: Fabrication and characterization of Ga-doped $\mathrm{ZnO}$ nanowire gas sensor for the detection of CO, Thin Solid Films, 518, 1190-1193, 2009.

Lao, J. Y., Huang, J. Y., Wang, D. Z., and Ren, Z. F.: ZnO Nanobridges and Nanonails, Nano. Lett., 3, 235, 2003.

Pearce, R., Soderlind, F., Hagelin, A., Kall, P., Yakimova, R., Spetz, E., Becker, E., and Skoglundh, M.: Effect of Water vapour on Gallium doped Zinc Oxide nanoparticle sensor gas response, Sensors IEEE, 2009.

Phan, D. and Chung, G.: Effects of defects in Ga-doped $\mathrm{ZnO}$ nanorods formed by a hydrothermal method on CO sensing properties, Sensors Actuat. B-Chem., 187, 191-197, 2013.

Shirakata, S., Sakemi, T., Awai, K., and Yamamoto, T.: Optical and electrical properties of ZNO films prepared by URT-IP method, Thin Solid Films, 445, 278-283, 2003.

Tanaka, M., Tsubone, D., and Yanagida, H.: Dependence of Electrical Conductivity of $\mathrm{ZnO}$ on Degree of Sintering, J. Am. Ceram. Soc., 59, 4-8, 1976.

Trung, D. D., Hoa, N. D., Tong, P. V., Duy, N. V., Dao, T. D., Chung, H. V., Nagao, T., and Hieu, N. V.: Effective decoration of $\mathrm{Pd}$ nanoparticles on the surface of $\mathrm{SnO}_{2}$ nanowires for enhancement of $\mathrm{CO}$ gas-sensing performance, J. Hazard. Mater., 265, 124-312, 2014.
Yamada, T., Ikeda, K., Kishimoto, S., Makino, H., and Yamamoto, T.: Effects of oxygen partial pressure on doping properties of Ga-doped $\mathrm{ZnO}$ films prepared by ion-plating with traveling substrate, Surface and Coatings Technology, 201, 4004-4007, 2006.

Yamada, T., Nebiki, T., Kishimoto, S., Makino, H., Awai, K., Narusawa, T., and Yamamoto, T.: Dependences of structural and electrical properties on thickness of polycrystalline Ga-doped $\mathrm{ZnO}$ thin films prepared by reactive plasma deposition, Superlattice Microst., 42, 68, 2007a.

Yamada, T., Miyake, A., Kishimoto, S., Makino, H., Yamamoto, N., and Yamamoto, T.: Low resistivity Ga-doped $\mathrm{ZnO}$ thin films of less than $100 \mathrm{~nm}$ thickness prepared by ion plating with direct current arc discharge, Appl. Phys. Lett., 91, 051915, $2007 \mathrm{~b}$.

Yamada, T., Makino, H., Yamamoto, N., and Yamamoto, T.: Ingrain and grain boundary scattering effects on electron mobility of transparent conducting polycrystalline Ga-doped $\mathrm{ZnO}$ films, J. Appl. Phys., 107, 123534, 2010.

Yamamoto, T., Song, H., Makino, H., and Yamamoto, T. N.: ECS Transactions, edited by: Misra, D., Bauza, D., Chen, Z., Chikyo, T., Iwai, H., Obeng, Y., and Datta, S., 45, 401-410, 2012.

Zhao, S. H., Wang, L. L., Wang, L., and Wang, Z. Y.: Synthesis and luminescence properties of $\mathrm{ZnO}: \mathrm{Tb} 3+$ nanotube arrays via electrodeposited method, Physica B, 405, 3200, 2010. 